\title{
Large deflection of a non-linear, elastic, asymmetric Ludwick cantilever beam subjected to horizontal force, vertical force and bending torque at the free end
}

\author{
Alberto Borboni - Diego De Santis
}

Received: 25 June 2013/ Accepted: 28 January 2014

(C) Springer Science+Business Media Dordrecht 2014

\begin{abstract}
The investigated cantilever beam is characterized by a constant rectangular cross-section and is subjected to a concentrated constant vertical load, to a concentrated constant horizontal load and to a concentrated constant bending torque at the free end. The same beam is made by an elastic non-linear asymmetric Ludwick type material with different behavior in tension and compression. Namely the constitutive law of the proposed material is characterized by two different elastic moduli and two different strain exponential coefficients. The aim of this study is to describe the deformation of the beam neutral surface and particularly the horizontal and vertical displacements of the free end cross-section. The analysis of large deflection is based on the Euler-Bernoulli bending beam theory, for which cross-sections, after the deformation, remain plain and perpendicular to the neutral surface; furthermore their shape and area do not change. On the stress viewpoint, the shear stress effect and the axial force effect are considered negligible in comparison with the bending effect. The mechanical model deduced from the identified hypotheses includes two kind of non-linearity: the first
\end{abstract}

A. Borboni $(\bowtie) \cdot$ D. De Santis

Mechanical and Industrial Engineering Department, Università degli Studi di Brescia, Via Branze, 38, 25123 Brescia, Italy

e-mail: alberto.borboni@ing.unibs.it due to the material and the latter due to large deformations. The mathematical problem associated with the mechanical model, i.e. to compute the bending deformations, consists in solving a non-linear algebraic system and a non-liner second order ordinary differential equation. Thus a numerical algorithm is developed and some examples of specific results are shown in this paper.

Keywords Large deflections - Asymmetric Ludwick constitutive law · Material nonlinearity $\cdot$ Geometrical non-linearity $\cdot$ Cantilever beam

\section{List of symbols}

$L \quad$ Initial length of the beam and length of the beam neutral curve, $(\mathrm{m})$

$b \quad$ Width of rectangular cross-section, (m)

$h \quad$ Height of rectangular cross-section, (m)

$F_{V} \quad$ Constant vertical force at the free end of the beam, $(\mathrm{N})$

$F_{H} \quad$ Constant horizontal force at the free end of the beam, $(\mathrm{N})$

$T \quad$ Constant bending torque at the free end of the beam, (Nm)

Oxyz Coordinate system of reference configuration

$O^{\prime} x^{\prime} y^{\prime} z^{\prime} \quad$ Coordinate system defined for each crosssection

$h_{1}, h_{2} \quad$ Quotes individuating the neutral axis of cross-section, (m) 
$E_{t} \quad$ Tensile Young modulus, (GPa)

$E_{c} \quad$ Compressive Young modulus, (GPa)

$n \quad$ Tensile non-linearity coefficient or tensile strain exponential coefficient

$m$

Compressive non-linearity coefficient or compressive strain exponential coefficient

$\sigma_{t} \quad$ Tensile stress, $(\mathrm{GPa})$

$\sigma_{c} \quad$ Compression stress, $(\mathrm{GPa})$

$\varepsilon_{t} \quad$ Positive strain

$\varepsilon_{c} \quad$ Negative strain

$\delta_{h} \quad$ Theoretical horizontal displacement of the free end, (m)

$\delta_{v} \quad$ Theoretical vertical displacement of the free end, (m)

$\delta_{h 1} \quad$ Horizontal displacement of the free end calculated by numerical algorithm given in this paper, $(\mathrm{m})$

$\delta_{v 1} \quad$ Vertical displacement of the free end calculated by numerical algorithm given in this paper, (m)

$\delta_{h 2} \quad$ Horizontal displacement of the free end calculated in Lewis and Monasa [5], (m)

$\delta_{v 2} \quad$ Vertical displacement of the free end calculated in Lewis and Monasa [5], (m)

$\delta_{h 3} \quad$ Horizontal displacement of the free end calculated in Bayakara et al. [8], (m)

$\delta_{v 3} \quad$ Vertical displacement of the free end calculated in Bayakara et al. [8], (m)

$\delta_{h 4} \quad$ Horizontal displacement of the free end calculated by ABACUS/CAE ${ }^{\circledR},(\mathrm{m})$

$\delta_{v 4} \quad$ Vertical displacement of the free end calculated by ABACUS/CAE ${ }^{\circledR},(\mathrm{m})$

$M \quad$ Bending moment, (Nm)

$S_{0}, S_{1} \quad$ Cross-sections delimiting an infinitesimal portion of the beam

$d s \quad$ Initial length of a horizontal fibre of an infinitesimal portion of the beam

$d \theta \quad$ Infinitesimal angle

$t \quad$ Position of a horizontal fibre of an infinitesimal portion of the beam, (m)

$L_{1} \quad$ Final length of a deformed horizontal fibre of an infinitesimal portion of the beam, (m)

$\rho \quad$ Radius of curvature of the neutral curve, (m)

$\sigma_{s} \quad$ Stress along $s$ axis, $(\mathrm{GPa})$

$\varepsilon_{s} \quad$ Strain along s axis

$f(x) \quad$ Analytical expression of the neutral curve of the beam, $(\mathrm{m})$

\section{Introduction}

The proposed work is connected with the fruitful scientific activity present in literature [1, 2]. Bisshopp and Drucker [3] derived the solution of large deflection for cantilever beams made of linear elastic material and subjected to a vertical concentrated load at the free end. Lo and Gupta [4] examined the bending problem of a nonlinear rectangular beam with large deflection; they considered linear elastic behavior for sections of the beam that deformed elastically, and a logarithmic function of strain is used for regions stressed beyond the elastic limit; the logarithmic function was approximated by a semi-logarithmic relation, which is only applicable for special cases. Lewis and Monasa [5] solved numerically the problem of large deflection of cantilever beams made of nonlinear elastic materials of the Ludwick type subjected to a vertical concentrated load at the free end. A closed-form solution of large deflection of cantilever beams made of Ludwick type material subjected to an end moment was obtained again by Lewis and Monasa [6]. Lee [7] computed a numerical solution of large deflection of cantilever beams made of Ludwick type material subjected to a combined loading consisting of a uniformly distributed load and a vertical concentrated load at the free end. Bayakara et al. [8] investigated the effect of bimodulus Ludwick type material behavior on the horizontal and vertical deflections at the free end of a thin cantilever beam under an end moment. A semi-exact solution was obtained by Solano-Carrillo [9] for large deflection of cantilever beams made of Ludwick type material subjected to a combined action of a uniformly distributed load and to a vertical concentrated force at the free end. Brojan et al. [10] studied the large deflections of nonlinearly elastic non-prismatic cantilever beams made of materials obeying the generalized Ludwick constitutive law. Holden [11] obtained the numerical solution to the problem of finite deflection of linear elastic cantilever beam with uniformly distributed load using a fourth order Runge-Kutta method. Byoung et al. [12] investigated large deflection of linear elastic cantilever beam of variable cross-section under combined loading by using Runge-Kutta method. Baker [13] obtained the large deflection profiles of linear elastic tapered 
cantilever under arbitrary distributed loads through a weighted residual solution of the governing BernoulliEuler equation. Prataph and Varadan [14] investigated the non-linear elastic large deflection of a cantilever beam with a vertical concentrated load at its free end, where the material of the beam follows a stress-strain law of the Ramberg-Osgood type. Varadan and Joseph [15] solved the problem of the large deflection of a cantilever beam made of Ramberg-Osgood type material under a moment at the free end. Recently the large and the small deformations of a non-linear functionally graded-material cantilever beam subjected to an end force were investigated by Kang and Li [16]. Chainarong Athisakul et al. [17] present a large deflection of variable-arc-length beams, which are made from nonlinear elastic materials, subjected to its uniform self-weight. The stress-strain relation of materials obeys the symmetric Ludwick constitutive law. Brojan et al. [18] study large deflections of slender, non-prismatic cantilever beams composed of a nonlinearly elastic Ludwick material with a different material behavior in tensile and compressive domain and subjected to a combined loading which consists of a non-uniformly distributed continuous load and a concentrated vertical force at the free end of the beam. Eren [19] calculated horizontal and largest vertical deflections for uniformly distributed loaded, simply supported beams made of Ludwick type nonlinear material. Curvature expression for elastic curve had been defined according to two different arc length functions.

The proposed work continues these researches paying attention to large deflection of a cantilever beam made of a non-linear elastic Ludwick material with different behavior in tension and compression. Different implementation of these results can be performed for applicative purposes, i.e. in the design of compliant mechanisms or microactuators with large deflections [20-22].

\section{Problem statement}

The investigated cantilever beam of length $L$ has a rectangular constant cross-section with base $b$ and height $\mathrm{h}$ and is subjected to a concentrated constant vertical force $\mathrm{F}_{\mathrm{V}}$, to a concentrated constant horizontal load $\mathrm{F}_{\mathrm{H}}$ and to a concentrated constant bending torque $\mathrm{T}$ at the free end. $\mathrm{F}_{\mathrm{H}}$ must be always combined with $\mathrm{F}_{\mathrm{V}}$

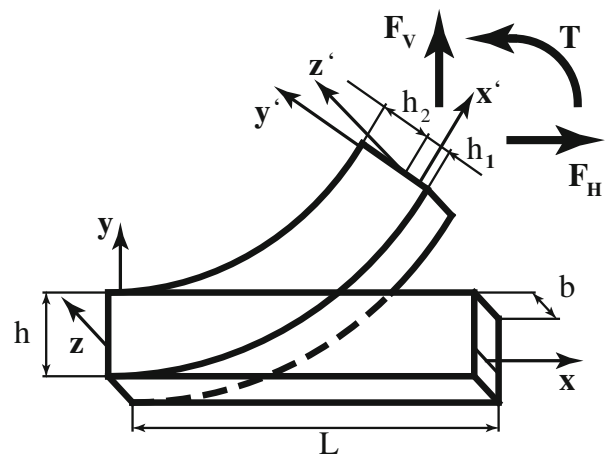

Fig. 1 Transition in large deflection of a cantilever beam from the initial configuration to the deformed configuration subjected to the $\mathrm{F}_{\mathrm{V}}, \mathrm{F}_{\mathrm{H}}$ and $\mathrm{T}$ loads

or $\mathrm{T}$, in order to avoid buckling phenomena. In Fig. 1 the transition in large deflection is shown from the initial configuration to the deformed configuration subjected to the $\mathrm{F}_{\mathrm{V}}, \mathrm{F}_{\mathrm{H}}$ and $\mathrm{T}$ loads. The former is the reference configuration and is placed in the Oxyz system of reference. The latter is the final configuration and is referred to Oxyz; in this configuration an $\mathrm{O}^{\prime} \mathrm{x}^{\prime} \mathrm{y}^{\prime} z^{\prime}$ coordinate system is defined for each crosssection with $\mathrm{x}^{\prime}$ axis orthogonal to the cross-section and $\mathrm{y}^{\prime}$ and $\mathrm{z}^{\prime}$ axes belonging to the cross-section. Particularly the $\mathrm{z}^{\prime}$ axis coincides with the neutral axis of the cross-section, it is defined by the intersection between the neutral surface of the beam and the cross-section and it is located by $h_{1}$ and $h_{2}$. Both dimensions $h_{1}$ and $\mathrm{h}_{2}$ are a priori unknown, they depend on the $\mathrm{x}$ coordinate according to the relation (1).

$h_{1}(x)+h_{2}(x)=h$

The beam is made by an elastic non-linear asymmetric Ludwick type material with different behavior in tension and compression, as proposed in [8]. Namely the constitutive law of the proposed material is characterized by two different elastic moduli and two different strain exponential coefficients as indicated in the constitutive law (2), where $\mathrm{E}_{\mathrm{t}}$ and $\mathrm{E}_{\mathrm{c}}$ are respectively the tensile Young modulus and the compressive Young modulus and where $\mathrm{n}$ and $\mathrm{m}$ are respectively the tensile non-linearity coefficient and the compressive non-linearity coefficients. $E_{t}, E_{c}, n$ and $\mathrm{m}$ are strictly positive. The considered constitutive law does not provide contractions and expansions along all directions perpendicular to the stress direction. Conventionally tensile stresses $\sigma_{\mathrm{t}}$ are positive, 


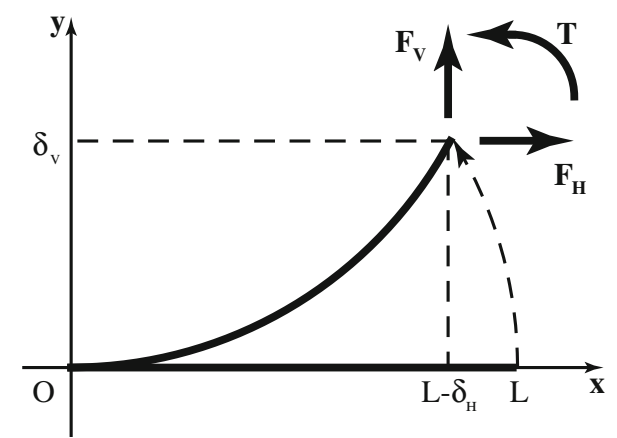

Fig. 2 Neutral curve of the cantilever beam in the initial and final configuration subjected to the $\mathrm{F}_{\mathrm{V}}, \mathrm{F}_{\mathrm{H}}$ and $\mathrm{T}$ loads

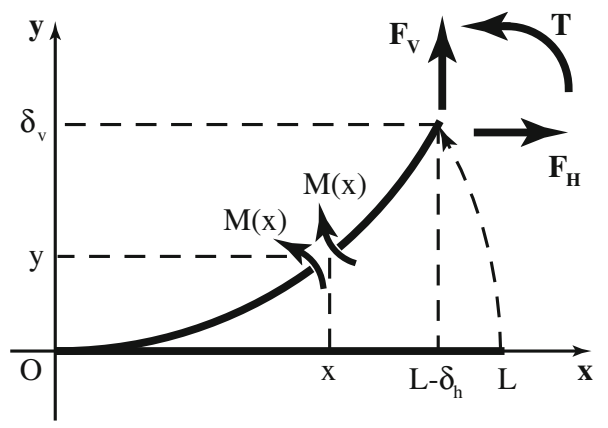

Fig. 3 Internal actions: each cross-section is considered to be subjected only to a bending moment $\mathrm{M}(\mathrm{x})$

compression stresses $\sigma_{\mathrm{c}}$ are negative, positive strains are indicated with $\varepsilon_{\mathrm{t}}$ and negative strains are indicated with $\varepsilon_{\mathrm{c}}$.

$$
\begin{gathered}
\sigma_{t}=E_{t}\left(\varepsilon_{t}\right)^{1 / n} \\
\sigma_{c}=-E_{c}\left(-\varepsilon_{c}\right)^{1 / m}
\end{gathered}
$$

\section{Problem formulation}

Only thin cantilever beams in large deflection are considered, and hypothesis of Euler-Bernoulli bending beam theory are used. Thus cross-sections, after the deformation, remain plain and perpendicular to the neutral surface and their shape and area do not change. For these reasons the beam is modelled by its neutral curve, that is defined by the intersection between beam neural surface and the $\mathrm{x}-\mathrm{y}$ plane, as shown in Fig. 2, where $\delta_{\mathrm{h}}$ and $\delta_{\mathrm{v}}$ are respectively the horizontal displacement and the vertical displacement of the free end.

On the internal stress viewpoint, the shear stress effect and the axial force effect are considered
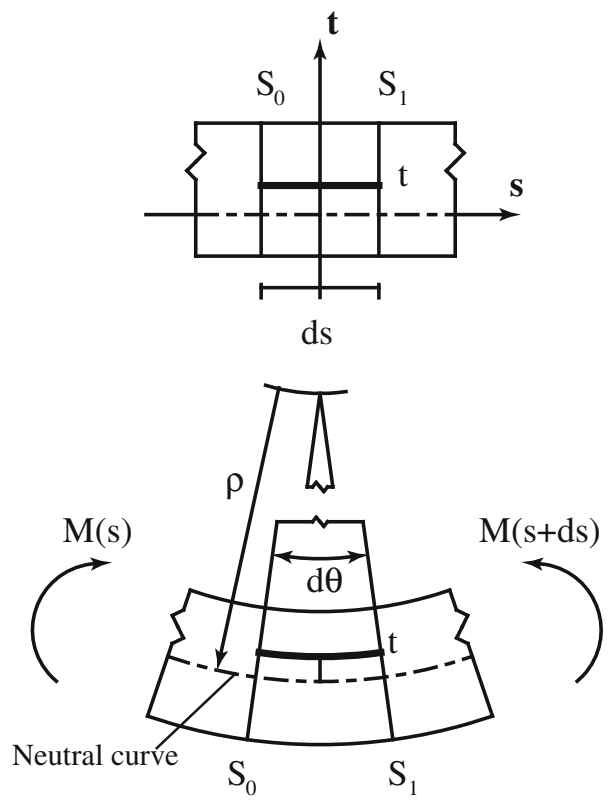

Fig. 4 Transition of an infinitesimal element of length ds and contained between $S_{0}$ and $S_{1}$ cross-sections, from the initial configuration to the deformed configuration and deformation of one its fibre

negligible in comparison with the bending effect. Thus, as shown in Fig. 3, in the deformed configuration each cross-section is considered to be subjected only to a bending moment $\mathrm{M}(\mathrm{x})$, that depends on the $\mathrm{x}$ coordinate and is given by the relation (3).

$M(x)=F_{V}\left(L-\delta_{h}-x\right)-F_{H}\left(\delta_{V}-y\right)+T$

In order to find the expression of strains, an infinitesimal portion of the deformed beam is considered. As shown in Fig. 4, this element of length ds is contained between the $S_{0}$ and $S_{1}$ cross-sections.

The transition of the infinitesimal element is shown in Fig. 4 from the initial configuration to the deformed configuration.

The horizontal fibre, shown in Fig. 4, in the reference configuration is ds long and it is far $\mathrm{t}$ from the neutral curve. After the deformation, its length, indicated with $L_{1}$, is given by the relation (4), where $\rho$ is the radius of curvature of the neutral curve and is defined in the expression (5). After combining the Eqs. (4) and (5), the relation (6) is obtained and it expresses $\mathrm{L}_{1}$ depending on the initial length ds of the fibre.

$L_{1}=[\rho(s)-t] d \theta$ 
$\rho(s)=\frac{d s}{d \theta}$

$L_{1}=d s-\frac{t}{\rho(s)} d s$

The general definition of strain is enunciated in (7) and, with the relation (6), it takes the form of the relation (8).

$\varepsilon_{s}=\frac{L_{1}-d s}{d s}$

$\varepsilon_{s}=-\frac{t}{\rho(s)}$

According to hypotheses on internal actions, for which every cross-section is considered to be subjected only to a bending moment $\mathrm{M}$, relations (9) and (10) can be written for each cross-section in the deformed configuration.

$$
\begin{aligned}
& \int_{A} \sigma_{s} d A=0 \\
& \int_{A} \sigma_{s} t d A=-M
\end{aligned}
$$

After distinguishing the compressed area from the tensile area of a generic cross-section, relations (9) and (10) can be expressed respectively as in (11) and (12).

$$
\begin{aligned}
& b \int_{-h_{1}}^{0} \sigma_{t} d t+b \int_{0}^{h_{2}} \sigma_{c} d t=0 \\
& b \int_{-h_{1}}^{0} \sigma_{t} t d t+b \int_{0}^{h_{2}} \sigma_{c} t d t=-M
\end{aligned}
$$

Equations (13) and (14) are obtained substituting relations (2), (3) and (8) in expressions (11) and (12).

$$
\begin{gathered}
E_{t} \frac{n}{n+1}\left(\frac{h_{1}}{\rho}\right)^{\frac{1}{n}} h_{1}-E_{c} \frac{m}{m+1}\left(\frac{h_{2}}{\rho}\right)^{\frac{1}{m}} h_{2}=0 \\
E_{t} \frac{n}{2 n+1}\left(\frac{h_{1}}{\rho}\right)^{\frac{1}{n}} h_{1}^{2}+E_{c} \frac{m}{2 m+1}\left(\frac{h_{2}}{\rho}\right)^{\frac{1}{m}} h_{2}^{2} \\
=\frac{F_{V}\left(L-\delta_{h}-x\right)-F_{H}\left(\delta_{V}-y\right)+T}{b}
\end{gathered}
$$

Equations (1), (13) and (14) represent a non-linear algebraic system with three unknown functions $\mathrm{h}_{1}(\mathrm{x})$, $h_{2}(x)$ and $\rho(x)$. The search of the system solution is made difficult because $\delta_{\mathrm{h}}, \delta_{\mathrm{v}}$ and $\mathrm{y}$ are a priori unknown.

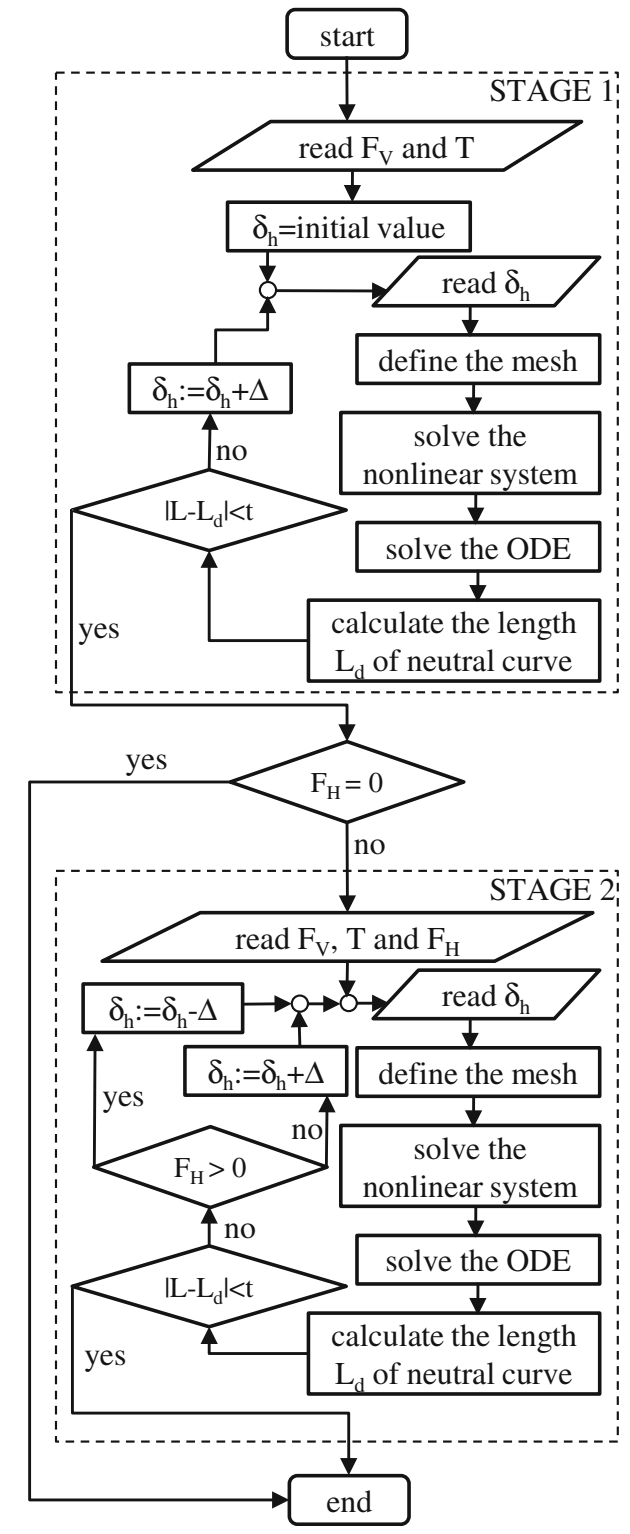

Fig. 5 Flowchart of the implemented algorithm

Thus a numerical algorithm is developed in two stages, as shown in the flowchart in Fig. 5. The first stage considers only the $\mathrm{F}_{\mathrm{V}}$ and $\mathrm{T}$ loads and assigns a tentative value to $\delta_{\mathrm{h}}$ and a mesh on the $\mathrm{x}$ axis, then it solves the non-linear system with the Newton-Raphson method for every point of the mesh and obtains three vectors, contained respectively values of $h_{1}(x)$, $\mathrm{h}_{2}(\mathrm{x})$ and $\rho(\mathrm{x})$. Successively, it solves, with the Euler method, the non-liner second order ordinary differential Eq. (15), which correlates $\rho(x)$ and the analytic 
Table $1 \delta_{\mathrm{h}}$ values of a cantilever beam made of annealed copper in large deflection

\begin{tabular}{llll}
\hline $\mathrm{F}_{\mathrm{V}}(\mathrm{N})$ & $\delta_{\mathrm{h} 1}(\mathrm{~m})$ & $\delta_{\mathrm{h} 2}(\mathrm{~m})$ & $\begin{array}{l}\left(\delta_{\mathrm{h} 1}-\delta_{\mathrm{h} 2}\right) / \\
\delta_{\mathrm{h} 1}(\%)\end{array}$ \\
\hline 9.42112 & 0.00103508 & 0.00103124 & 0.37 \\
17.90013 & 0.01437780 & 0.01429512 & 0.58 \\
34.01026 & 0.09121844 & 0.09105900 & 0.17 \\
44.06934 & 0.140700 & 0.14001496 & 0.08 \\
51.98238 & 0.17213208 & 0.17206468 & 0.04 \\
\hline
\end{tabular}

$\delta_{\mathrm{h} 1}$ is $\delta_{\mathrm{h}}$ calculated by numerical algorithm given in this paper and $\delta_{\mathrm{h} 2}$ is $\delta_{\mathrm{h}}$ calculated in Lewis and Monasa [5], with $\mathrm{F}_{\mathrm{H}}=0 \mathrm{~N}, \mathrm{~T}=0 \mathrm{Nm}, \mathrm{E}_{\mathrm{t}}=\mathrm{E}_{\mathrm{c}}=0.46 \mathrm{GPa}, \mathrm{n}=\mathrm{m}=2.16$, $\mathrm{b}=0.0254 \mathrm{~m}, \mathrm{~h}=0.00635 \mathrm{~m}$ and $\mathrm{L}=0.508 \mathrm{~m}$

expression $f(x)$ of the neutral curve of the beam, with initial conditions (16).

Once vector of $f(x)$ is known, the first stage proceeds with the evaluation of the used value of $\delta_{\mathrm{h}}$, verifying the neutral curve length is different from the initial length $\mathrm{L}$ for a prefixed tolerance. If the verification is negative, $\delta_{\mathrm{h}}$ increases of a prefixed value and the first stage starts again. Once the value of $\delta_{\mathrm{h}}$ due to $\mathrm{F}_{\mathrm{V}}$ and $\mathrm{T}$ is known, the second stage starts considering $\mathrm{F}_{\mathrm{V}}, \mathrm{T}$ and $\mathrm{F}_{\mathrm{H}}$ loads and considering final $\delta_{\mathrm{h}}$ of the first stage as initial value, working in the same manner of the first stage.

Once the value of $\delta_{\mathrm{h}}$ is known, $\delta_{\mathrm{v}}$ is given by the relation (17).

$$
\begin{aligned}
& \frac{1}{\rho}=\frac{\frac{d^{2} f}{d x^{2}}}{\left[1+\left(\frac{d f}{d x}\right)^{2}\right]^{3 / 2}} \\
& f(0)=0 ; \quad f^{\prime}(0)=0 \\
& \delta_{v}=f\left(L-\delta_{h}\right)
\end{aligned}
$$

In the case $E_{t}$ and $E_{c}$ have the same value and nonlinearity coefficients $\mathrm{n}$ and $\mathrm{m}$ are both equal to one, the algorithm gives $\delta_{\mathrm{h}}$ and $\delta_{\mathrm{v}}$ values for a classic cantilever beam in large deflections.

\section{Comparison with less reach models}

In order to test the algorithm, $\delta_{\mathrm{h}}$ and $\delta_{\mathrm{v}}$ are calculated for a cantilever beam made of symmetric Ludwick type material with same behavior in tension and compression like annealed copper subjected to a
Table $2 \delta_{\mathrm{v}}$ values of a cantilever beam made of annealed copper in large deflection

\begin{tabular}{llll}
\hline $\mathrm{F}_{\mathrm{V}}(\mathrm{N})$ & $\delta_{\mathrm{v} 1}(\mathrm{~m})$ & $\delta_{\mathrm{v} 2}(\mathrm{~m})$ & $\begin{array}{l}\left(\delta_{\mathrm{v} 1}-\delta_{\mathrm{v} 2}\right) / \\
\delta_{\mathrm{v} 1}(\%)\end{array}$ \\
\hline 9.42112 & 0.03042169 & 0.03034284 & 0.26 \\
17.90013 & 0.11239629 & 0.11219180 & 0.18 \\
34.01026 & 0.27147425 & 0.27143964 & 0.01 \\
44.06934 & 0.32710396 & 0.32722312 & -0.04 \\
51.98238 & 0.35573994 & 0.35593020 & -0.05 \\
\hline
\end{tabular}

$\delta_{\mathrm{v} 1}$ is $\delta_{\mathrm{v}}$ calculated by numerical algorithm given in this paper and $\delta_{\mathrm{v} 2}$ is $\delta_{\mathrm{v}}$ calculated in Lewis and Monasa [5], with $\mathrm{F}_{\mathrm{H}}=0 \mathrm{~N}, \mathrm{~T}=0 \mathrm{Nm} \mathrm{E}_{\mathrm{t}}=\mathrm{E}_{\mathrm{c}}=0.46 \mathrm{GPa}, \mathrm{n}=\mathrm{m}=2.16$, $\mathrm{b}=0.0254 \mathrm{~m}, \mathrm{~h}=0.00635 \mathrm{~m}$ and $\mathrm{L}=0.508 \mathrm{~m}$

Table $3 \delta_{\mathrm{h}}$ values of a cantilever beam made of annealed copper in large deflection

\begin{tabular}{llll}
\hline $\mathrm{E}_{\mathrm{c}}(\mathrm{GPa})$ & $\delta_{\mathrm{h} 1}(\mathrm{~m})$ & $\delta_{\mathrm{h} 3}(\mathrm{~m})$ & $\left(\delta_{\mathrm{h} 1}-\delta_{\mathrm{h} 3}\right) / \delta_{\mathrm{h} 1}(\%)$ \\
\hline 50 & 0.09274 & 0.09371 & -1.05 \\
75 & 0.05976 & 0.06023 & -0.79 \\
125 & 0.03486 & 0.03508 & -0.63 \\
150 & 0.02894 & 0.02912 & -0.62 \\
175 & 0.02481 & 0.02496 & -0.60 \\
\hline
\end{tabular}

$\delta_{\mathrm{h} 1}$ is $\delta_{\mathrm{h}}$ calculated by numerical algorithm given in this paper and $\delta_{\mathrm{h} 3}$ is $\delta_{\mathrm{h}}$ calculated in Bayakara et al. [8], with $\mathrm{E}_{\mathrm{t}}=100 \mathrm{GPa}, \mathrm{T}=20 \mathrm{Nm}, \mathrm{n}=1, \mathrm{~m}=0.8, \mathrm{~b}=0.02 \mathrm{~m}$, $\mathrm{h}=0.005 \mathrm{~m}$ and $\mathrm{L}=0.4 \mathrm{~m}$

Table $4 \delta_{\mathrm{v}}$ values of a cantilever beam made of annealed copper in large deflection

\begin{tabular}{llll}
\hline $\mathrm{E}_{\mathrm{c}}(\mathrm{GPa})$ & $\delta_{\mathrm{v} 1}(\mathrm{~m})$ & $\delta_{\mathrm{v} 3}(\mathrm{~m})$ & $\left(\delta_{\mathrm{v} 1}-\delta_{\mathrm{v} 3}\right) / \delta_{\mathrm{v} 1}(\%)$ \\
\hline 50 & 0.21580 & 0.21670 & -0.42 \\
75 & 0.17906 & 0.17977 & -0.40 \\
125 & 0.14004 & 0.14055 & -0.36 \\
150 & 0.12831 & 0.12877 & -0.36 \\
175 & 0.11925 & 0.11967 & -0.35 \\
\hline
\end{tabular}

$\delta_{\mathrm{v} 1}$ is $\delta_{\mathrm{v}}$ calculated by numerical algorithm given in this paper and $\delta_{\mathrm{v} 3}$ is $\delta_{\mathrm{v}}$ calculated in Bayakara et al. [8], with $\mathrm{E}_{\mathrm{t}}=100 \mathrm{GPa}, \mathrm{T}=20 \mathrm{Nm}, \mathrm{n}=1, \mathrm{~m}=0.8, \mathrm{~b}=0.02 \mathrm{~m}$, $\mathrm{h}=0.005 \mathrm{~m}$ and $\mathrm{L}=0.4 \mathrm{~m}$

vertical force at the free end. Tables 1 and 2 compare values respectively of $\delta_{\mathrm{h}}$ and $\delta_{\mathrm{v}}$ calculated by the proposed algorithm to values indicated in Lewis and Monasa [5], for some values of the constant vertical force $\mathrm{F}_{\mathrm{V}}$. Values obtained by the proposed algorithm 


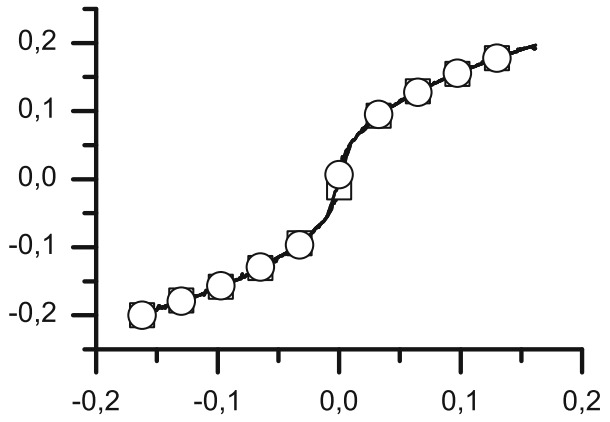

Fig. 6 Diagram stress-strain of annealed copper (squares) characterized using Marlow form of potential energy (circles) in ABACUS/CAE ${ }^{\circledR}$

are indicated with $\delta_{\mathrm{h} 1}$ and $\delta_{\mathrm{v} 1}$. Values obtained in Lewis and Monasa [5] are indicated with $\delta_{\mathrm{h} 2}$ and $\delta_{\mathrm{v} 2}$. Values obtained by the proposed algorithm and values indicated in Lewis and Monasa [5] are very close.

A similar test is performed for a cantilever beam made of an asymmetric Ludwick type material subjected to a bending torque at the free end. Tables 3 and 4 compare values respectively of $\delta_{\mathrm{h}}$ and $\delta_{\mathrm{v}}$ calculated by the proposed algorithm to values indicated in Bayakara et al. [8], for some values of the compressive Young modulus $\mathrm{E}_{\mathrm{c}}$. Values obtained by the proposed algorithm are indicated with $\delta_{\mathrm{h} 1}$ and $\delta_{\mathrm{v} 1}$. Values obtained in Bayakara et al. [8] are indicated with $\delta_{\mathrm{h} 3}$ and $\delta_{\mathrm{v} 3}$. Values obtained by the proposed algorithm and values indicated in Bayakara et al. [8] are very close.

\section{FEM validation}

In order to validate the numerical algorithm given in this paper, the horizontal displacement $\delta_{\mathrm{h}}$ and the vertical displacement $\delta_{\mathrm{v}}$ are calculated using the FEM software ABACUS/CAE ${ }^{\circledR}$ for a beam made of annealed copper subjected to a vertical force $\mathrm{F}_{\mathrm{V}}$ at the free end. In ABACUS/CAE ${ }^{\circledR}$ the investigated cantilever beam is discretized using the Hex method, i.e. the beam is subdivided in parallelepipeds. The constrain section is realized by blocking all nodes of that section. The vertical constant load is realized by four equal forces applied on the nodes of the four corners of the free section. Each of the four forces is equal to a quarter of $\mathrm{F}_{\mathrm{V}}$. In order to characterize annealed copper material, Marlow form of the

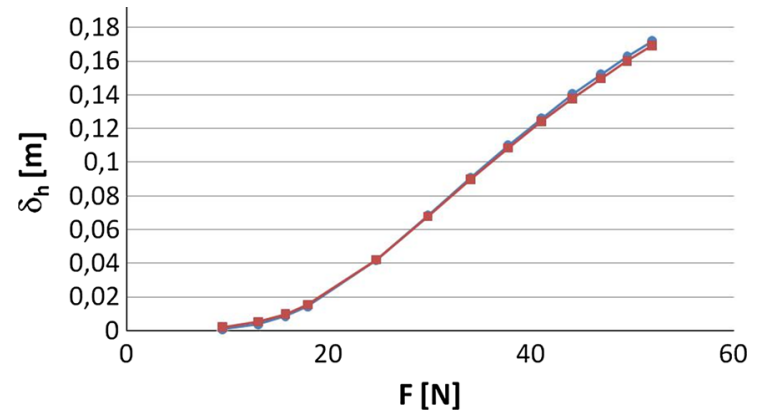

Fig. 7 Graphical comparison between $\delta_{\mathrm{h} 1}$ (circle line) and $\delta_{\mathrm{h} 4}$ (square line) values of a cantilever beam made of annealed copper in large deflection. $\delta_{\mathrm{h} 1}$ is $\delta_{\mathrm{h}}$ calculated by numerical algorithm given in this paper and $\delta_{\mathrm{h} 4}$ is $\delta_{\mathrm{h}}$ calculated by ABAQUS/CAE ${ }^{\circledR}$

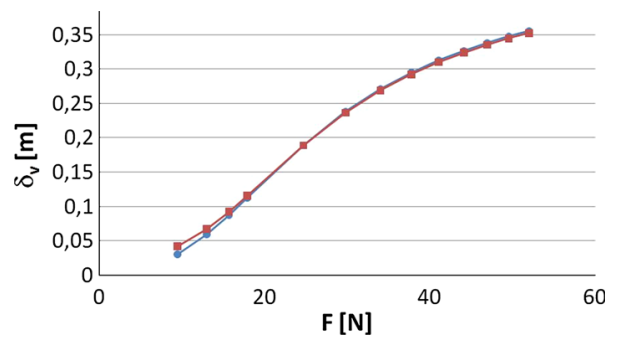

Fig. 8 Graphical comparison between $\delta_{\mathrm{v} 1}$ (circle line) and $\delta_{\mathrm{v} 4}$ (square line) values of a cantilever beam made of annealed copper in large deflection. $\delta_{\mathrm{v} 1}$ is $\delta_{\mathrm{v}}$ calculated by numerical algorithm given in this paper and $\delta_{\mathrm{v} 4}$ is $\delta_{\mathrm{v}}$ calculated by ABAQUS/CAE ${ }^{\circledR}$

potential energy is used in $\mathrm{ABACUS} / \mathrm{CAE}^{\circledR}$, as shown in Fig. 6.

Values obtained by the proposed algorithm, indicated with $\delta_{\mathrm{h} 1}$ and $\delta_{\mathrm{v} 1}$, and values calculated by ABACUS/CAE ${ }^{\circledR}$, indicated with $\delta_{\mathrm{h} 4}$ and $\delta_{\mathrm{v} 4}$, are very close, as shown in Figs. 7, 8. Some slight differences are due to the Marlow form of the potential used to characterize the proposed materials.

\section{Numerical results and discussion}

Some numerical results of $\delta_{\mathrm{h}}$ and $\delta_{\mathrm{v}}$, for a cantilever beam made of an asymmetric Ludwick type material subjected to $\mathrm{T}, \mathrm{F}_{\mathrm{V}}$ and $\mathrm{F}_{\mathrm{H}}$ at the free end, computed with the proposed algorithm and indicated with $\delta_{\mathrm{h} 1}$ and $\delta_{\mathrm{v} 1}$, are presented in Tables 5, 6, 7, 8, 9, 10, 11, 12, 13 and 14 to examine the role of the main geometrical and mechanical parameters that characterize the 
Table $5 \delta_{\mathrm{h} 1}$ and $\delta_{\mathrm{v} 1}$ calculated for different values of initial length $\mathrm{L}$ of the beam, with $\mathrm{b}=0.02 \mathrm{~m}, \mathrm{~h}=0.005 \mathrm{~m}, \mathrm{n}=1.2$, $\mathrm{m}=0.8, \mathrm{E}_{\mathrm{t}}=100 \mathrm{GPa}, \mathrm{E}_{\mathrm{c}}=125 \mathrm{GPa}, \mathrm{F}_{\mathrm{V}}=30 \mathrm{~N}, \mathrm{~F}_{\mathrm{H}}=$ $30 \mathrm{~N}, \mathrm{~T}=15 \mathrm{Nm}$

\begin{tabular}{lll}
\hline $\mathrm{L}(\mathrm{m})$ & $\delta_{\mathrm{h} 1}(\mathrm{~m})$ & $\delta_{\mathrm{v} 1}(\mathrm{~m})$ \\
\hline 0.2 & 0.0019406 & 0.024675 \\
0.3 & 0.0073280 & 0.057860 \\
0.4 & 0.018064 & 0.10449 \\
0.5 & 0.035442 & 0.16208 \\
0.6 & 0.059317 & 0.22778 \\
\hline
\end{tabular}

Table $6 \delta_{\mathrm{h} 1}$ and $\delta_{\mathrm{v} 1}$ calculated for different values of height $\mathrm{h}$ of rectangular cross-section, with $\mathrm{L}=0.4 \mathrm{~m}, \mathrm{~b}=0.02 \mathrm{~m}$, $\mathrm{n}=1.2, \mathrm{~m}=0.8, \mathrm{E}_{\mathrm{t}}=100 \mathrm{GPa}, \mathrm{E}_{\mathrm{c}}=125 \mathrm{GPa}, \mathrm{F}_{\mathrm{V}}=30 \mathrm{~N}$, $\mathrm{F}_{\mathrm{H}}=30 \mathrm{~N}, \mathrm{~T}=15 \mathrm{Nm}$

\begin{tabular}{lll}
\hline $\mathrm{h}(\mathrm{m})$ & $\delta_{\mathrm{h} 1}(\mathrm{~m})$ & $\delta_{\mathrm{v} 1}(\mathrm{~m})$ \\
\hline 0.0040 & 0.049045 & 0.16662 \\
0.0045 & 0.029608 & 0.13175 \\
0.0050 & 0.018064 & 0.10449 \\
0.0055 & 0.011369 & 0.083451 \\
0.0060 & 0.0073502 & 0.067376 \\
\hline
\end{tabular}

Table $7 \delta_{\mathrm{h} 1}$ and $\delta_{\mathrm{v} 1}$ calculated for different values of the width $\mathrm{b}$ of rectangular cross-section, with $\mathrm{L}=0.4 \mathrm{~m}, \mathrm{~h}=0.005 \mathrm{~m}$, $\mathrm{n}=1.2, \mathrm{~m}=0.8, \mathrm{E}_{\mathrm{t}}=100 \mathrm{GPa}, \mathrm{E}_{\mathrm{c}}=125 \mathrm{GPa}, \mathrm{F}_{\mathrm{V}}=30 \mathrm{~N}$, $\mathrm{F}_{\mathrm{H}}=30 \mathrm{~N}, \mathrm{~T}=15 \mathrm{Nm}$

\begin{tabular}{lll}
\hline $\mathrm{b}(\mathrm{m})$ & $\delta_{\mathrm{h} 1}(\mathrm{~m})$ & $\delta_{\mathrm{v} 1}(\mathrm{~m})$ \\
\hline 0.010 & 0.048749 & 0.16617 \\
0.015 & 0.027813 & 0.12807 \\
0.020 & 0.018064 & 0.10449 \\
0.025 & 0.012846 & 0.088418 \\
0.030 & 0.0095927 & 0.076851 \\
\hline
\end{tabular}

system. Specifically, Table 5 reports that $\delta_{\mathrm{h} 1}$ and $\delta_{\mathrm{v} 1}$ increase with increasing values of initial length $L$ of the beam. Table 6 reports that $\delta_{\mathrm{h} 1}$ and $\delta_{\mathrm{v} 1}$ decrease with increasing values of height $h$ of rectangular crosssection. Table 7 report that $\delta_{\mathrm{h} 1}$ and $\delta_{\mathrm{v} 1}$ decrease with increasing values of the width $b$ of rectangular crosssection. Table 8 reports that $\delta_{\mathrm{h} 1}$ and $\delta_{\mathrm{v} 1}$ decrease with increasing values of tensile Young modulus $E_{t}$. Table 9 reports that $\delta_{\mathrm{h} 1}$ and $\delta_{\mathrm{v} 1}$ decrease with increasing values of compressive Young modulus $\mathrm{E}_{\mathrm{c}}$. Table 10 reports that $\delta_{\mathrm{h} 1}$ and $\delta_{\mathrm{v} 1}$ decrease with increasing values of tensile non-linearity coefficient
Table $8 \delta_{\mathrm{h} 1}$ and $\delta_{\mathrm{v} 1}$ calculated for different values of tensile Young modulus $\mathrm{E}_{\mathrm{t}}$, with $\mathrm{L}=0.4 \mathrm{~m}, \mathrm{~h}=0.005 \mathrm{~m}, \mathrm{~b}=0.02 \mathrm{~m}$, $\mathrm{n}=1.2, \mathrm{~m}=0.8, \mathrm{E}_{\mathrm{c}}=125 \mathrm{GPa}, \mathrm{F}_{\mathrm{V}}=30 \mathrm{~N}, \mathrm{~F}_{\mathrm{H}}=30 \mathrm{~N}$, $\mathrm{T}=15 \mathrm{Nm}$

\begin{tabular}{lll}
\hline $\mathrm{E}_{\mathrm{t}}(\mathrm{GPa})$ & $\delta_{\mathrm{h} 1}(\mathrm{~m})$ & $\delta_{\mathrm{v} 1}(\mathrm{~m})$ \\
\hline 50 & 0.025289 & 0.12270 \\
75 & 0.020586 & 0.11115 \\
100 & 0.018064 & 0.10449 \\
125 & 0.016583 & 0.099984 \\
150 & 0.015496 & 0.096759 \\
\hline
\end{tabular}

Table $9 \delta_{\mathrm{h} 1}$ and $\delta_{\mathrm{v} 1}$ calculated for different values of compressive Young modulus $\mathrm{E}_{\mathrm{c}}$, with $\mathrm{L}=0.4 \mathrm{~m}, \mathrm{~h}=0.005 \mathrm{~m}$, $\mathrm{b}=0.02 \mathrm{~m}, \mathrm{n}=1.2, \mathrm{~m}=0.8, \mathrm{E}_{\mathrm{t}}=100 \mathrm{GPa}, \mathrm{F}_{\mathrm{V}}=30 \mathrm{~N}$, $\mathrm{F}_{\mathrm{H}}=30 \mathrm{~N}, \mathrm{~T}=15 \mathrm{Nm}$

\begin{tabular}{lll}
\hline $\mathrm{E}_{\mathrm{c}}(\mathrm{GPa})$ & $\delta_{\mathrm{h} 1}(\mathrm{~m})$ & $\delta_{\mathrm{v} 1}(\mathrm{~m})$ \\
\hline 75 & 0.031567 & 0.13590 \\
100 & 0.023120 & 0.11740 \\
125 & 0.018064 & 0.10449 \\
150 & 0.014812 & 0.094833 \\
175 & 0.012457 & 0.087358 \\
\hline
\end{tabular}

Table $10 \delta_{\mathrm{h} 1}$ and $\delta_{\mathrm{v} 1}$ calculated for different values of tensile non-linearity coefficient $\mathrm{n}$, with $\mathrm{L}=0.4 \mathrm{~m}, \mathrm{~h}=0.005 \mathrm{~m}$, $\mathrm{b}=0.02 \mathrm{~m}, \mathrm{~m}=0.8, \mathrm{E}_{\mathrm{t}}=100 \mathrm{GPa}, \mathrm{E}_{\mathrm{c}}=125 \mathrm{GPa}, \mathrm{F}_{\mathrm{V}}=$ $30 \mathrm{~N}, \mathrm{~F}_{\mathrm{H}}=30 \mathrm{~N}, \mathrm{~T}=15 \mathrm{Nm}$

\begin{tabular}{lll}
\hline$n$ & $\delta_{\mathrm{h} 1}(\mathrm{~m})$ & $\delta_{\mathrm{v} 1}(\mathrm{~m})$ \\
\hline 0.8 & 0.069946 & 0.19411 \\
1.0 & 0.030664 & 0.13418 \\
1.2 & 0.018064 & 0.10449 \\
1.4 & 0.013279 & 0.089781 \\
1.6 & 0.011027 & 0.082024 \\
\hline
\end{tabular}

Table $11 \delta_{\mathrm{h} 1}$ and $\delta_{\mathrm{v} 1}$ calculated for different values of compressive non-linearity coefficient $\mathrm{m}$, with $\mathrm{L}=0.4 \mathrm{~m}, \mathrm{~h}=$ $0.005 \mathrm{~m}, \mathrm{~b}=0.02 \mathrm{~m}, \mathrm{n}=1.2, \mathrm{E}_{\mathrm{t}}=100 \mathrm{GPa}, \mathrm{E}_{\mathrm{c}}=125 \mathrm{GPa}$, $\mathrm{F}_{\mathrm{V}}=30 \mathrm{~N}, \mathrm{~F}_{\mathrm{H}}=30 \mathrm{~N}, \mathrm{~T}=15 \mathrm{Nm}$

\begin{tabular}{lll}
\hline $\mathrm{m}$ & $\delta_{\mathrm{h} 1}(\mathrm{~m})$ & $\delta_{\mathrm{v} 1}(\mathrm{~m})$ \\
\hline 0.70 & 0.047186 & 0.16326 \\
0.75 & 0.029271 & 0.13116 \\
0.80 & 0.018064 & 0.10449 \\
1.0 & 0.0029865 & 0.043378 \\
1.2 & 0.00069780 & 0.021601 \\
\hline
\end{tabular}


Table $12 \delta_{\mathrm{h} 1}$ and $\delta_{\mathrm{v} 1}$ calculated for different values of constant vertical force $\mathrm{F}_{\mathrm{V}}$ at the free end of the beam, with $\mathrm{L}=0.4 \mathrm{~m}, \mathrm{~h}=0.005 \mathrm{~m}, \mathrm{~b}=0.02 \mathrm{~m}, \mathrm{n}=1.2, \mathrm{~m}=0.8$, $\mathrm{E}_{\mathrm{t}}=100 \mathrm{GPa}, \mathrm{E}_{\mathrm{c}}=125 \mathrm{GPa}, \mathrm{F}_{\mathrm{H}}=30 \mathrm{~N}, \mathrm{~T}=15 \mathrm{Nm}$

\begin{tabular}{lll}
\hline $\mathrm{F}_{\mathrm{V}}(\mathrm{N})$ & $\delta_{\mathrm{h} 1}(\mathrm{~m})$ & $\delta_{\mathrm{v} 1}(\mathrm{~m})$ \\
\hline 10 & 0.011898 & 0.084116 \\
20 & 0.014876 & 0.094534 \\
30 & 0.018064 & 0.10449 \\
40 & 0.021508 & 0.11393 \\
50 & 0.025080 & 0.12294 \\
\hline
\end{tabular}

Table $13 \delta_{\mathrm{h} 1}$ and $\delta_{\mathrm{v} 1}$ calculated for different values of constant horizontal force $\mathrm{F}_{\mathrm{H}}$ at the free end of the beam, with $\mathrm{L}=0.4 \mathrm{~m}, \mathrm{~h}=0.005 \mathrm{~m}, \mathrm{~b}=0.02 \mathrm{~m}, \mathrm{n}=1.2, \mathrm{~m}=0.8$, $\mathrm{E}_{\mathrm{t}}=100 \mathrm{GPa}, \mathrm{E}_{\mathrm{c}}=125 \mathrm{GPa}, \mathrm{F}_{\mathrm{V}}=30 \mathrm{~N}, \mathrm{~T}=15 \mathrm{Nm}$

\begin{tabular}{lll}
\hline $\mathrm{F}_{\mathrm{H}}(\mathrm{N})$ & $\delta_{\mathrm{h} 1}(\mathrm{~m})$ & $\delta_{\mathrm{v} 1}(\mathrm{~m})$ \\
\hline 10 & 0.020674 & 0.11144 \\
20 & 0.019323 & 0.10786 \\
30 & 0.018064 & 0.10449 \\
40 & 0.016984 & 0.10125 \\
50 & 0.015993 & 0.098173 \\
\hline
\end{tabular}

Table $14 \delta_{\mathrm{h} 1}$ and $\delta_{\mathrm{v} 1}$ calculated for different values of constant bending torque $\mathrm{T}$ at the free end of the beam, with $\mathrm{L}=0.4 \mathrm{~m}, \mathrm{~h}=0.005 \mathrm{~m}, \mathrm{~b}=0.02 \mathrm{~m}, \mathrm{n}=1.2, \mathrm{~m}=0.8$, $\mathrm{E}_{\mathrm{t}}=100 \mathrm{GPa}, \mathrm{E}_{\mathrm{c}}=125 \mathrm{GPa}, \mathrm{F}_{\mathrm{V}}=30 \mathrm{~N}, \mathrm{~F}_{\mathrm{H}}=30 \mathrm{~N}$

\begin{tabular}{lll}
\hline $\mathrm{T}(\mathrm{Nm})$ & $\delta_{\mathrm{h} 1}(\mathrm{~m})$ & $\delta_{\mathrm{v} 1}(\mathrm{~m})$ \\
\hline 5 & 0.0064206 & 0.064129 \\
10 & 0.011676 & 0.084845 \\
15 & 0.018064 & 0.10449 \\
20 & 0.025705 & 0.12304 \\
25 & 0.034292 & 0.14071 \\
\hline
\end{tabular}

n. Table 11 reports that $\delta_{\mathrm{h} 1}$ and $\delta_{\mathrm{v} 1}$ decrease with increasing values of compressive non-linearity coefficient $\mathrm{m}$. Table 12 reports that $\delta_{\mathrm{h} 1}$ and $\delta_{\mathrm{v} 1}$ increase with increasing values of constant vertical force $\mathrm{F}_{\mathrm{V}}$ at the free end of the beam. Table 13 reports that $\delta_{\mathrm{h} 1}$ and $\delta_{\mathrm{v} 1}$ decrease with increasing values of constant horizontal force $\mathrm{F}_{\mathrm{H}}$ at the free end of the beam. Table 14 reports that $\delta_{\mathrm{h} 1}$ and $\delta_{\mathrm{v} 1}$ increase with increasing values of constant bending torque $\mathrm{T}$ at the free end of the beam.

\section{Conclusions}

The finite horizontal and vertical displacement in large deflections are obtained in this work for the free end of a cantilever beam, made of asymmetric Ludwick type material and subjected to a vertical constant force, to a horizontal constant force and to a bending constant at the free end. The problem involves both material and geometrical non-linearity and solution to such problems can be found with numerical methods. The proposed algorithm proved to be a technique to solve the resulting the non-linear algebraic system and the non-liner second order ordinary differential equation governing the problem. After verifying a proper agreeing with the literature and obtaining a validation by FEM software ABACUS/CAE ${ }^{\circledR}$, in order to investigate the effect of the different material behavior on the horizontal and vertical displacements of the free end cross-section, numerical results are computed for different values of the applied loads.

\section{References}

1. Borboni A, De Santis D, Faglia R (2010) Large deflection of a non-linear, elastic, asymmetric Ludwick cantilever beam. ASME 2010 10th Biennial Conference on Engineering Systems Design and Analysis, ESDA2010, 2: 99-106. DOI: 10.1115/ESDA2010-24257

2. Borboni A, De Santis D, Faglia R (2010) Large deflection of a non-linear, elastic, asymmetric Ludwick cantilever beam. 16th Quadrennial ASME Conference of Theoretical and Applied Mechanics

3. Bisshopp KE, Drucker DC (1945) Large deflections of cantilever beams. Q Appl Math 3:272-275

4. Lo CC, Gupta D (1978) Bending of a nonlinear rectangular beam in large deflection. J Appl Mech ASME 45:213-215

5. Lewis G, Monasa F (1981) Large deflections of cantilever beams of nonlinear materials. Comput Struct 14:357-360

6. Lewis G, Monasa F (1982) Large deflections of cantilever beams of non-linear materials of the Ludwick type subjected to an end moment. Int J Non-Linear Mech 17:1-6

7. Lee K (2002) Large deflections of cantilever beams of nonlinear elastic material under a combined loading. J NonLinear Mech 37:439-443

8. Bayakara C, Güven U, Bayer I (2005) Large deflections of a cantilever beam of nonlinear bimodulus material subjected to an end moment. J Reinf Plast Comp 24:1321-1326

9. Solano-Carrillo E (2009) Semi-exact solutions for large deflections of cantilever beams of non-linear elastic behaviour. Int J Non-Linear Mech 44:253-256

10. Brojan M, Videnic T, Kosel F (2009) Large deflections of nonlinearly elastic non-prismatic cantilever beams made from materials obeying the generalized Ludwick constitutive law. Meccanica 44:733-739 
11. Holden JT (1972) On the finite deflections of thin beams. Int J Solids Struct 8:133-135

12. Byoung KL, Wilson JF, Sang JO (1993) Elastica of cantilevered beams with variable cross sections. Int J Non-Linear Mech 28:579-589

13. Baker G (1993) On the large deflections of non-prismatic cantilevers with a finite depth. Comput Struct 46:365-370

14. Prathap G, Varadan TK (1976) The inelastic large deformation of beams. J Appl Mech 43:689-690

15. Varadan TL, Joseph D (1987) Inelastic finite deflections of cantilever beams. J Aeronaut Soc India 39:39-41

16. Kang YA, Li XF (2009) Bending of functionally graded cantilever beam with power-law non-linearity subjected to an end force. Int J Non-Linear Mech 44:696-703

17. Chainarong A, Boonchai $\mathrm{P}$, Gissanachai J, and Somchai $\mathrm{C}$ (2012) Effect of material nonlinearity on large deflection of variable-arc-length beams subjected to uniform self-weight. Mathematical Problems in Engineering 2012. Article ID 345461

18. Brojan M, Cebron M, Kosel F (2012) Large deflections of non-prismatic nonlinearly elastic cantilever beams subjected to non-uniform continuous load and a concentrated load at the free end. Acta Mech Sin 28(3):863-869

19. Eren I (2013) Analyses of large deflections of simply supported nonlinear beams, for various arc length functions. Arabian J Sci Eng 38(4):947-952

20. Amici C, Borboni A, Faglia R (2010) A compliant PKM mesomanipulator: kinematic and dynamic analyses advances in mechanical engineering 2010, art. no. 706023. doi: 10.1155/2010/706023

21. Amici C, Borboni A, Faglia R, Fausti D, Magnani PL (2008) A parallel compliant meso-manipulator for finger rehabilitation treatments: Kinematic and dynamic analysis. 2008 IEEE/RSJ International Conference on Intelligent Robots and Systems, IROS, art. no. 4651029, pp. 735-740. doi: 10. 1109/IROS.2008.4651029

22. Borboni A, De Santis D, Faglia R (2006) Stochastic analysis of free vibrations in piezoelectric bimorphs. In : Proceedings of 8th Biennial ASME Conference on Engineering Systems Design and Analysis, ESDA2006 